Trees (1991) 5: $90-94$

\title{
Comparative studies on ectomycorrhizae synthesized with various in vitro techniques using Picea abies and two Hebeloma species
}

\author{
Ivano Brunner \\ Swiss Federal Institute for Forest, Snow and Landscape Research (WSL), 8903 Birmensdorf, Switzerland
}

Received November 9, 1990/Accepted February 6, 1991

Summary. Various in vitro synthesis techniques with Picea abies and two Hebeloma species showed that structures of the mantle and Hartig net of synthesized ectomycorrhizae within the given two fungus species are stable. However, thickness of mantle, and penetration depth and number of hyphal cell rows between cortical cells of the Hartig net are dependent on techniques and substrates. Porous glass balls as substrate in the Erlenmeyer technique seem to suppress or delay mantle and Hartig net formation. With the other techniques (growth pouch, open cuvette, Erlenmeyer with a vermiculite-peat moss mixture) development of the mantle is simultaneous with or shortly in advance of Hartig net formation. The ectomycorrhizae of the two tested Hebeloma species are similar and cannot be morphologically differentiated by the in vitro techniques used.

Key words: Picea abies - Hebeloma crustuliniforme Hebeloma cylindrosporum - Ectomycorrhizal syntheses Characteristic-stability

\section{Introduction}

There is a long lasting dispute as to whether in vitro synthesized and naturally occurring ectomycorrhizae can be compared and, if so whether the methods used for synthesizing symbioses influence morphologically important features under certain cultural conditions (Harley and Smith 1983). Only recently Kottke (1986) showed for a few Picea- and Larix-ectomycorrhizae that naturally and synthesized symbioses do not differ significantly from each other and that syntheses can be used to identify ectomycorrhizae. However, Melin's cultural method, which uses aseptic Erlenmeyer flasks, was applied. However, the question as to whether various synthesis methods influence the morphology and anatomy of ectomycorrhizae remains to be answered.
Synthesis methods range from aseptic, semiaseptic to nonsterile cultural conditions. Erlenmeyer flask or glass tube methods are commonly used to synthesize ectomycorrhizae in an aseptic environment to describe the ultrastructure and morphology of symbioses (e.g. Kottke and Oberwinkler 1986a). The semiaseptic growth pouch technique is commonly used to describe the ontogeny of ectomycorrhizae (e.g. Melville et al. 1987). Both methods, however, are suitable for evaluating ability to form ectomycorrhizae with a given putative host-plant (e.g. Brunner 1987; Brunner et al. 1990). The growth pouch method is often criticized as being too artificial due to the lack of a soil-like matrix that can act as a morphogenetic agent (Harley and Smith 1983). Thus, the resulting ectomycorrhizae may not be relevant for comparing naturally occurring with in vitro synthesized symbioses.

Important morphological features of ectomycorrhizae are Hartig net, mantle, emanating hyphae and cystidia, and rhizomorphs (Agerer et al. 1986; Kottke and Oberwinkler 1986b). Anatomically, the structure of the Hartig net, the structure of tangential longitudinal sections of the hyphal mantle, and rhizomorphs can vary. Agerer et al. (1986) observed three types of Hartig net and Haug (1987) reported 12 different types of tangential longitudinal sections of the hyphal mantle. Rhizomorphs may vary from single aggregated hyphae to highly complex and differentiated cords with a central transport xylem similar to those of higher plants (Agerer et al. 1986).

The objectives of this study were to synthesize ectomycorrhizae with various methods or various substrates, to describe the arising symbioses and to distinguish between morphologically and anatomically stable and variable characters of ectomycorrhizae.

\section{Materials and methods}

\section{Plant material}

Seeds of Picea abies (L.) Karst. originated from Dielsdorf (canton of Zürich, Switzerland) and were collected in 1977. For germination, the seeds were surface sterilized for $30 \mathrm{~min}$ in $30 \% \mathrm{H}_{2} \mathrm{O}_{2}$ and placed on 
water agar plates. After 2-3 weeks the seedlings could be used for synthesis experiments.

\section{Fungal material}

Mycelia of Hebeloma crustuliniforme (Bull. ex St. Amans) Quél and H. cylindrosporum Romagn. were taken from the WSL culture collection. Both isolates were originally obtained from France. For the Erlenmeyer and open cuvette techniques fungal materials were pregrown for 20 days on a shaker in $125 \mathrm{ml}$ Erlenmeyer flasks containing $50 \mathrm{ml}$ modified Melin-Norkrans solution (MMN; Marx and Bryan 1975) including glucose $(10 \mathrm{~g} /)$ and malt $(3 \mathrm{~g} /)$. Afterwards, fungal mycelia were homogenized with a blender and introduced into Erlenmeyer flasks or cuvettes using an inversed pipette. For the growth pouch technique fungal discs were grown in advance on solid MMN-media for 5 days.

\section{Synthesis experiments}

The synthesis experiments were carried out in a growth chamber with a $16 \mathrm{~h}$ day period (PAR: $100 \mu \mathrm{E} \cdot \mathrm{m}^{-2} \cdot \mathrm{s}^{-1}$ ) at $20^{\circ} \mathrm{C}$ and $70 \%$ humidity. The duration of the experiments varied between 43 and 218 days (Table 1). Only Hebeloma cylindrosporum inocula were used within the Erlenmeyer techniques using a vermiculite-peat moss mixture and within the growth pouch technique (Table 1).

Erlenmeyer flask technique. Erlenmeyer flasks $(500 \mathrm{ml})$ were filled with a vermiculite-peat moss mixture $(200 \mathrm{ml}-30 \mathrm{ml})$ or with $250 \mathrm{ml}$ porous glass balls (Schott, FRG; Siran, 2-3 mm in diameter) and with $150 \mathrm{ml}$ $\mathrm{MMN}$-solution and autoclaved. $\mathrm{pH}$ values ranged between 5.5 with the vermiculite-peat moss mixture and 7.0 with the porous glass balls. Fungal inocula were introduced and allowed to grow for 34 days prior to seedling introduction.

Open cuvette technique. Stainless steel open cuvettes similar to those described in Schüepp et al. (1987) were used but the cuvettes were chambered for individual seedlings. For this technique seedlings were pregrown for 34 days in Erlenmeyer flasks containing a vermiculite-peat moss mixture and $\mathrm{MMN}$-solution. The $\mathrm{pH}$ value was 5.5. Autoclaved cuvettes were filled with the seedlings including the substrate from the Erlenmeyer flasks and inoculated with fungal material. Sterile distilled water was added frequently.

Growth pouch technique. Autoclaved polyethylene pouches $13 \times 16 \mathrm{~cm}$ (Cellpack, Switzerland) including a glass fiber paper with an activated charcoal paper disc attached (Schleicher and Schuell, Switzerland), similar to those described in Kottke et al. (1987), were filled with $10 \mathrm{ml}$ MMN (but without glucose and malt) and with one seedling. The $\mathrm{pH}$ value was 6.5. After 2 months, when the root systems were developed, four to six fungus inocula were placed in the vicinity of the short roots and another $10 \mathrm{ml} \mathrm{MMN}$ (including $5 \mathrm{~g} / \mathrm{l}$ glucose, no malt) was added.

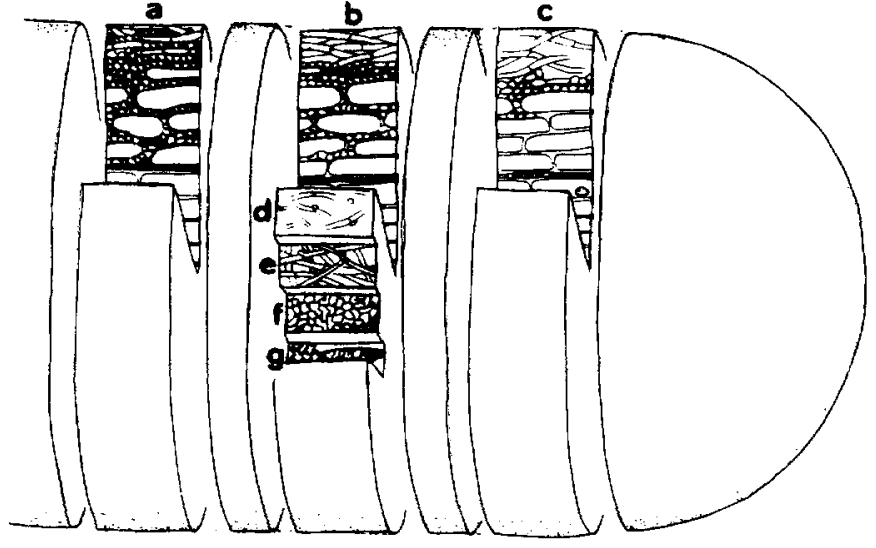

Fig. $1 \mathrm{a}-\mathrm{g}$. Positions of longitudinal sections through synthesized $\mathrm{He}$ beloma $\times$ Picea abies ectomycorrhizae (compare Weiss 1988). Central sections: a Basal portion, $\mathbf{b}$ Middle portion, and $\mathbf{c}$ Apical portion. Tangential sections: $\mathbf{d}$ Emanating hyphae, $\mathbf{e}$ Structure of outer layer of the mantle, $f$ Structure of the inner layer of the mantle, and $g$ Structure of Hartig net

Two strips of foam were introduced to provide air space. Sterile distilled water was added frequently.

\section{Root material}

Ectomycorrhizal rootlets were fixed in $2.5 \%$ glutaraldehyde, dehydrated in alcohol, embedded in glycol-methacrylate, longitudinally sectioned $(1.5 \mu)$, and stained with Giemsa for chitinoid material. Drawings were made with the aid of a Wild drawing tube. Morphological comparisons of mantle and Hartig net were made with basal, middle, and apical portions of central longitudinal sections (Fig. 1). Anatomical comparisons were made between emanating hyphae, and the outer and inner layers of the mantle and Hartig net and tangential longitudinal sections from the middle portion (Fig. 1)

\section{Results}

\section{Colonization of root tips}

Seedlings and fungus inocula in all employed synthesis methods grew well and contact between roots and hyphae was likely to occur. In growth pouches first contacts of, e.g. Hebeloma crustuliniforme and short roots could be observed within 4 days after fungus inoculation. Hyphae

Table 1. Occurrence of mantle and Hartig net at basal (b), middle (m), and apical (a) portions of synthesized Hebeloma $\times$ Picea abies ectomycorrhizae

\begin{tabular}{|c|c|c|c|c|c|c|c|c|}
\hline \multirow[t]{2}{*}{ Technique } & \multirow[t]{2}{*}{ Substrate } & \multirow{2}{*}{$\begin{array}{l}\text { Duration } \\
\text { (days) }\end{array}$} & \multicolumn{3}{|c|}{ Mantle } & \multicolumn{3}{|c|}{ Hartig net } \\
\hline & & & $\mathrm{b}$ & $\mathrm{m}$ & a & $\mathrm{b}$ & $\mathrm{m}$ & a \\
\hline Erlenmeyer & Vermiculite-peat moss & 43 & $\mathrm{x}$ & $(x)$ & - & $\mathrm{x}$ & $(x)$ & - \\
\hline Erlenmeyer & Vermiculite-peat moss & 83 & $\mathrm{x}$ & $\mathrm{x}$ & $(x)$ & $\mathrm{x}$ & $\mathrm{x}$ & - \\
\hline Erlenmeyer & Porous glass balls & 66 & $(\mathrm{x})$ & - & - & $\mathrm{x}$ & $\mathrm{x}$ & - \\
\hline Open cuvettes & & 46 & $\mathrm{x}$ & $\mathrm{x}$ & $\mathrm{x}$ & $\mathrm{x}$ & - & - \\
\hline \multicolumn{9}{|c|}{ H. cylindrosporum } \\
\hline Erlenmeyer & Vermiculite-peat moss & 83 & $\mathrm{x}$ & $\mathrm{x}$ & - & $\mathrm{x}$ & $\mathrm{x}$ & - \\
\hline Growth pouch & & 71 & $x$ & $\mathrm{x}$ & $\mathrm{x}$ & $\mathrm{x}$ & $\mathrm{x}$ & $(\mathrm{x})$ \\
\hline Growth pouch & & 218 & $\mathrm{x}$ & $\mathrm{x}$ & $\mathrm{x}$ & $\mathrm{x}$ & $\mathrm{x}$ & $(\mathrm{x})$ \\
\hline
\end{tabular}

In parentheses: feature not observed in all analysed material 

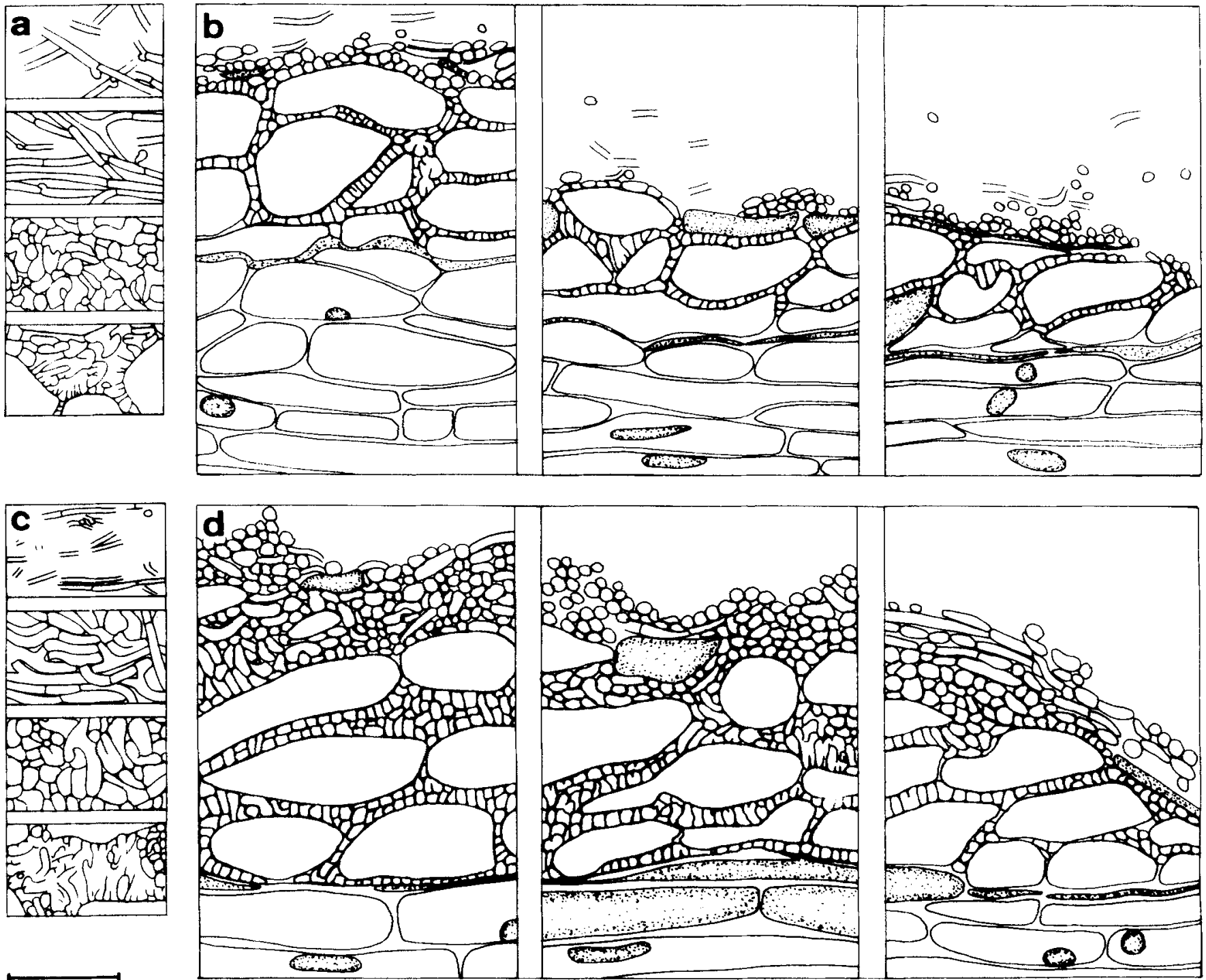

Fig. 2 a-d. Line drawings of longitudinal sections through Hebeloma $\times$ Picea abies ectomycorrhizae synthesized with the growth pouch tech nique. Scale $10 \mu$. Positions of sections according to Fig. 1. a, b He-

grew, probably directed by root exudates, to short roots and followed the main roots to colonize most of the remaining short roots.

\section{Mantle and Hartig net formation}

Mantles and Hartig nets were formed in all treatments, at least in distal portions of root tips (Table 1). However, mantle and Hartig net formation at the proximal portion of root tips occurred mainly in growth pouch techniques (Table 1). In treatments using other techniques these features were delayed, suppressed, or interrupted by metacutization (Kottke and Oberwinkler 1986b).

\section{Ectomycorrhizae of Hebeloma crustuliniforme $\times$ Picea abies (Fig. 2a, b)}

Morphology. Root tips are monopodial, up to 3-4 $\mu$ long and $0.3-0.5 \mu$ thick, straight, cylindrical, with rounded beloma crustuliniforme $\times$ Picea abies ectomycorrhizae, 72 days. c, $\mathbf{d}$ Hebeloma cylindrosporum $\times$ Picea abies ectomycorrhizae, 71 days

apices. The surface is smooth, occasionally covered with densely interwoven and emanating hyphae, and rhizomorphs were not observed. Root tips and their apices were white. No differences between various synthesis techniques could be seen. With the Erlenmeyer technique using porous glass balls the root tips were only loosely covered with hyphae and mantle formation was delayed or suppressed.

Emanating hyphae. Emanating hyphae are loosely interwoven, thin-walled, hyaline, $2-4 \mu$ broad, and clamp connections are present.

Mantle. The mantle is composed of two distinct layers. The outer layer is prosenchymatous with hyphae loosely to tightly interlaced, hyphal cells are $7 \mu$ and up long and $2-4 \mu$ broad, and clamp connections are present. The inner layer close to the cortical cells is synenchymatous with hyphae tightly interlaced and fitting together like a jigsaw 
puzzle, hyphal cells are 2-7 $\mu$ broad, and clamp connections were not observed. Thickness of mantles varied between treatments. Root tips in the Erlenmeyer flask technique using porous glass balls showed the thinnest, while those grown on vermiculite and peat moss developed thickest mantles. Meristematic root apices are in general poorly covered by fungal hyphae and a Hartig net is never developed. Zones of metacutizations in symbiosis with Hebeloma crustuliniforme occurred only in growth pouches. Only once, after 150 days, was the cortex zone proximal to the metacutis invaded by fungal hyphae and a Hartig net formed.

Hartig net. The Hartig net is composed of distinct fingerlike structures (palmettes), penetrating mostly up to the endodermis. One or as many as three hyphal cells are between the host cells, and hyphal cells and lobes of palmettes are 2-6 $\mu$ broad. A poor Hartig net development occurred in the open cuvette technique and in the Erlenmeyer flask technique using porous glass balls.

\section{Ectomycorrhizae of Hebeloma cylindrosporum $\times$ Picea abies (Fig. 2c,d)}

Morphology. Root tips are monopodial, up to 3-4 $\mu$ long and $0.3-0.5 \mu$ thick, straight, cylindrical, with rounded apices. The surface is smooth, occasionally covered with densely interwoven and emanating hyphae, and rhizomorphs were not observed. Root tips and their apices were white. No differences between various synthesis techniques could be seen.

Emanating hyphae. Emanating hyphae are loosely interwoven, thin-walled, hyaline, $2-4 \mu$ broad, and clamp connections are present.

Mantle. The mantle is composed of two distinct layers. The outer layer is prosenchymatous with hyphae loosely to tightly interlaced, hyphal cells are $7 \mu$ and up long and $2-4 \mu$ broad, and clamp connections are present. The inner layer close to the cortical cells is synenchymatous with hyphae tightly interlaced and fitting together like a jigsaw puzzle, hyphal cells are 2-7 $\mu$ broad, and clamp connections were not observed. Thickness of the mantle varied between treatments. Root tips in growth pouches after 71 days showed the thickest, while those grown on vermiculite and peat moss in Erlenmeyer flasks developed thinnest mantles. Meristematic root apices in general are poorly covered by fungal hyphae and a Hartig net is never developed. Zones of metacutizations occurred in all treatments with Hebeloma cylindrosporum.

Hartig net. The Hartig net is composed of distinct fingerlike structures, penetrating mostly up to the endodermis. One or as many as three hyphal cells are between the host cells, and hyphal cells and lobes of palmettes are $2-6 \mu$ broad.

\section{Discussion}

Although Hebeloma crustuliniforme and H.cylindrosporum are used frequently to synthesize ectomycorrhizae, adequate descriptions of the morphology of syntheses with Picea abies are lacking in the literature. However, syntheses with these two Hebeloma species and Pinus (Piché and Fortin 1982; Wong and Fortin 1989), Larix (Wong and Fortin 1989), Pseudotsuga (Trappe 1967), Dryas (Melville et al. 1987), Populus (Godbout and Fortin 1985), Alnus (Godbout and Fortin 1983; Brunner et al. 1990), or Quercus (Voiry 1981) have been described. Some characteristics are influenced very strongly by host trees (e.g. dichotomous branching pattern within Pinus, formation of paraepidermal Hartig net within Angiosperms) and some characteristics are stable and not dependent on host trees (e.g. features of the hyphal mantle). The presence of small white bodies similar to sclerotia where only reported by Voiry (1981) and thus their formation conditions are uncertain. A comparison of the presented results with other studies using trees other than P.abies as hosts is therefore difficult.

The similarities of the synthesized ectomycorrhizae in this study were striking and obvious, although techniques, substrated and species of fungi varied. Morphologically, almost no differences could be detected. The color, one of the features considered, is according to Agerer et al. (1986), Zak (1973), and Dominik (1969) one of the most stable (within one fungus-host relationship) and thus useful characteristics for ectomycorrhiza characterization. Even the color may not be diagnostic as shown by Massicotte et al. (1989) with syntheses between Laccaria bicolor (Maire) Orton and Pinus resinosa Ait. or Betula alleghaniensis Britt., both ectomycorrhizae having a mantle with purple hyphae. However, Trappe (1967) observed within Rhizopogon colossus A. H. Smith - Pseudotsuga menziesii (Mirb.) Franco ectomycorrhizae that the color changes with aging from white through light orange to brown. Similar observations have been reported by Egli and Kälin (1990) when they photographed naturally grown ectomycorrhizae over a period of 2 years. Therefore, color as an important characteristic of the morphology must be treated carefully since not enough data is available for general statements on its characteristic stability.

Anatomically, the structure of the mantle (in tangential longitudinal sections) and Hartig net in the present work is stable and does not differ between techniques used. Concerning the structure of the mantle, similar observations have been made by Haug (1987), who states that mantle structures of one given fungal species do not change due to various environmental conditions and age. Thus, mantle structure is useful to characterize ectomycorrhizae. Hartig net structure, on the other hand, remains stable even among different fungal species (Blasius et al. 1986) and therefore, as already stated by Zak (1973), is not sufficiently distinctive to be a useful characteristic to characterize an ectomycorrhiza. Since these structural features cannot be influenced by various environmental or various cultural conditions, they can be considered as static organs.

Mantle formation in the presented observations is simultaneous or shortly in advance of Hartig net formation, and only delayed in systems with porous glass balls. This observation is in agreement with results demonstrated by Melville et al. (1987) with Hebeloma cylindrosporum and Dryas integrifolia (Vahl.) but clearly stands in contrast to 
results presented by Nylund and Unestam (1982) with Piloderma croceum Erikss. and Hjortst. and Picea abies. Ontogenetically formation of ectomycorrhizae within one fungus-host relationship might be a stable feature and, as described above, not dependent on cultural and environmental conditions.

Other features such as thickness of mantle and penetration depth of Hartig net are considered as variable (Zak 1973). They also vary strongly in the present study and no relations to synthesis techniques, to synthesis substrates or to synthesis duration can be deduced. Kottke (1986), Weiss (1988), and Moore et al. (1989) confirm these observations. Only the occurrence of porous glass balls as substrate seem to suppress or delay mantle and Hartig net formation distinctly. The use of porous glass balls, however, is problematic for synthesis experiments, since $\mathrm{pH}$ values are difficult to control because of the constant loss of alcaline silicaceous residues of the substrate. Growth speed, therefore, depends, among many factors, on cultural conditions. Formation of rhizomorphs and mantle cystidia did not occur in the present study and thus provide no evidence.

The presence of a metacutis is usually linked with a root apex covered by a mantle. This fact supports the observation that a metacutis layer indicates a dormant stage (Kottke and Oberwinkler 1986b) and, therefore, hyphal growth can catch up with the root tip growth. Factors which may induce formation of metacutis seem not to be controllable with the system used.

The use of various techniques also involves various cultural conditions with open or closed systems and various substrates. Parameters which might influence ectomycorrhizal formation were not detected in this study (e.g. various oxygen- and carbon dioxide-concentrations, temperature, irradiation, moisture, $\mathrm{pH}$ ).

In conclusion, ectomycorrhizae synthesized with the two Hebeloma species in growth pouches, in open cuvettes, and in Erlenmeyer flasks cannot distinctly be distinguished on a morphological or anatomical basis. Therefore, the growth pouch method may be stated to be just as suitable as the Erlenmeyer flask method for comparing ectomycorrhizae from nature and from in vitro syntheses. Soil impedance caused by a compact soil or an artificial matrix such as vermiculite or porous glass balls does not act as a distinct morphogenetic agent.

Acknowledgements. I am grateful to S. Egli for providing laboratory facilities and reviewing this manuscript, Mrs. B. Schneider for sectioning and staining the ectomycorrhizae, Mrs. M. Zollinger for assistance, and Mrs. M. Sieber for correcting the English text. This study was supported by the WaBoLu II project of the Swiss Federal Institute of Technology (ETH) and by the WSL project V 412.89.1.

\section{References}

Agerer R, Brand F, Gronbach E (1986) Die exakte Kenntnis der Ectomykorrhizen als Voraussetzung für Feinwurzeluntersuchungen im Zusammenhang mit dem Waldsterben. Allg Forstz 20: 497-504

Blasius D, Feil W, Kottke I, Oberwinkler F (1986) Hartig net formation in fully ensheated ectomycorrhizas. Nord J Bot 6: 837-842
Brunner I (1987) Pilzökologische Untersuchungen in Wiesen und Brachland in der Nordschweiz (Schaffhauser Jura). Veröff Geobot Inst ETH Stiftung Rübel Zürich 92: 1-241

Brunner I, Brunner F, Miller OK Jr (1990) Ectomycorrhizal synthesis with Alaskan Alnus tenuifolia. Can J Bot 68: $761-767$

Dominik T (1969) Key to ectotrophic mycorrhizae. Folia For Pol Ser A 15: $309-328$

Egli S, Kälin I (1990) The root window - a technique for observing mycorrhizae on living trees. Agric Ecosystems Environ 28: 107-110

Godbout C, Fortin JA (1983) Morphological features of synthesized ectomycorrhizae of Alnus crispa and A. rugosa. New Phytol 94: $249-262$

Godbout C, Fortin JA (1985) Synthesized ectomycorrhizae of aspen: fungal genus level of structural characterization. Can J Bot 63: $252-$ 262

Harley JL, Smith SE (1983) Mycorrhizal symbiosis. Academic Press, London

Haug I (1987) Licht- und elektronenmikroskopische Untersuchungen an Mykorrhizen von Fichtenbeständen im Schwarzwald. Dissertation, Tübingen

Kottke I (1986) Charakterisierung und Identifizierung von Mykorrhizen. In: Einsele G (ed) Das landschaftsökologische Forschungsprojekt Naturpark Schönbuch. Deutsche Forschungsgemeinschaft, Forschungsbericht, Weinheim, pp 463-485

Kottke I, Oberwinkler F (1986 a) Root-fungus association observed on initial stages of mantle formation and Hartig net establishment in mycorrhizas of Amanita muscaria in Picea abies in pure culture. Can J Bot 64: 2348 -2354

Kottke I, Oberwinkler F (1986 b) Mycorrhiza of forest trees - structure and function. Trees $1-24$

Kottke I, Guttenberger M, Hampp R, Oberwinkler F (1987) An in vitro method for establishing mycorrhizae on coniferous tree seedlings. Trees 1: 191- 194

Marx DH, Bryan WC (1975) Growth and ectomycorrhizal development of lobolly pine seedlings in fumigated soil infested with the fungal symbiont Pisolithus tinctorius. For Sci 21: 245-254

Massicotte HB, Peterson RL, Melville LH (1989) Hartig net structure of ectomycorrhizae synthesized between Laccaria bicolor (Tricholomataceae) and two hosts: Betula alleghaniensis (Betulaceae) and Pinus resinosa (Pinaceae). Am J Bot 76: 1654- 1667

Melville LH, Massicotte HB, Peterson RL (1987) Ontogeny of early stages of ectomycorrhizae synthesized between Dryas integrifolia and Hebeloma cylindrosporum. Bot Gaz 148: 332 - 341

Moore LM, Jansen AE, Van Griensven LJLD (1989) Pure culture synthesis of ectomycorrhizas with Cantharelluscibarius. Acta Bot Neerl 38: $273-278$

Nylund J, Unestam T (1982) Structure and physiology of ectomycorrhizae. 1. The process of mycorrhiza formation in Norway spruce in vitro. New Phytol 91: 63-79

Piché Y, Fortin JA (1982) Development of mycorrhizae, extramatrical mycelium and sclerotia on Pinus strobus seedlings. New Phytol 91: $211-220$

Schüepp H, Miller DD, Bodmer M (1987) A new technique for monitoring hyphal growth of vesicular-arbuscular mycorrhizal fungi through soil. Trans Br Mycol Soc 89: $429 \ldots 435$

Trappe J (1967) Pure culture synthesis of Douglas-fir mycorrhizae with species of Hebeloma, Suillus, Rhizopogon, and Astraeus. For Sci 13: $121-130$

Voiry H (1981) Classification morphologique des ectomycorhizes du chêne et du hêtre dans le nord-est de la France. Eur J For Path 11: $284-299$

Weiss M (1988) Ektomykorrhizen von Picea abies. Synthese, Ontogenie und Reaktion auf Umweltschadstoffe. Dissertation, München

Wong KKY, Fortin JA (1989) A petri dish technique for the aseptic synthesis of ectomycorrhizae. Can J Bot 67: 1713-1716

Zak B (1973) Classification of ectomycorrhizae. In: Marks GC, Kozlowski TT (eds) Ectomycorrhizae. Academic Press, New York, pp $43-78$ 